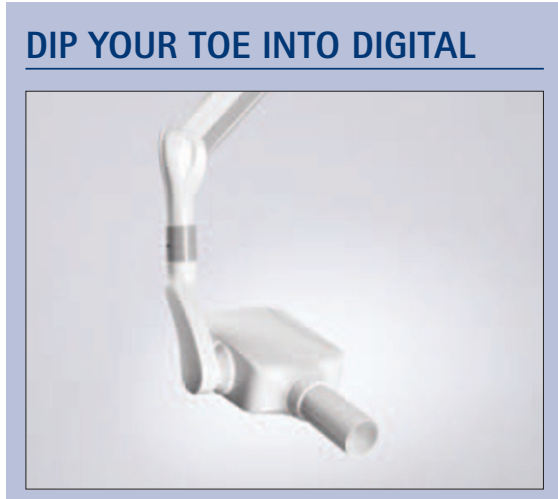

Takara Belmont has developed an X-ray unit that delivers an improved user interface, keeping faith with their tradition of simple operation.

The new Belray II system is engineered for accurate positioning, with excellent stability and reach. The control panel is compact and smooth with a single piece membrane for easy cleaning. It boasts innovative design parameters, including a recessed focal spot allowing for a longer source-toskin distance.

The Belray II unit offers great functionality and compatibility. Switching from film to digital is as easy as the press of a button on its intuitive control panel, enabling flexibility and adaptation all in the same unit. The zero drift scissor arm can be neatly stowed away against the wall when not in use, and the control panel can be mounted outside the room, operated by remote control or a hand exposure switch.

The Belray 097 is a great entry level machine for those practitioners just wanting to 'dip their toe into digital waters', but who want the reassurance of knowing that the unit is backed by Belmont, so excellent stability and zero drift are a constant. Reader response number 53

\section{CHEWING GUM WITH XYLITOL}

Xylitol has a growing reputation as one of the most powerful preventive tools in the battle against dental caries. Recent studies have even suggested that by regularly chewing xylitol-based gum, mothers can significantly reduce the chance of spreading plaque-causing bacteria to their children. This is because xylitol has a unique chemical composition that is unfavourable to the metabolism of mutans streptococci - the bacteria most closely associated with tooth decay.

\section{NEW COURSES FOR 2012}

The UCL Eastman Dental Institute has now launched 25 new CPD short courses for 2012.

Designed for all UK dental professionals, the courses range between one to five days and are repeated throughout the year. As some of the courses take place over consecutive days, the courses are ideal for professionals travelling from outside London or even from overseas.

There are topics such as lasers in dentistry, as well as courses linking
As a leading manufacturer of xylitol-based products, Spry produces a range of dentifrices, mints and gums designed to benefit any comprehensive oral hygiene regime. These products include Spry Fluoride Toothpaste, Spry Xlear Oral Rinse and Spry Chewing Gum - sweetened only with xylitol to promote overall good oral and dental care. Chewed after meals, the sugar-free chewing gum has been scientifically proven to help fight the bacteria that produce cavities. Reader response number 54 in with the four domains as required for GDC revalidation. With online learning and new extended CPD courses for all members of the dental team, the portfolio is sure to have something to challenge and stimulate everyone.

With over 140 widely experienced teaching staff who are all highly respected within their chosen field of excellence, the Eastman is also delighted to announce the superb facilities on the newly opened 4th floor are now fully operational. Reader response number 55

\section{LOW SHRINKAGE TECHNOLOGY}

Incorporating the best of industrial monomer innovation from DuPont, Kalore features an exclusive low shrinkage technology. On a microscopic level, this means that during and after polymerisation, adhesion between the fillers and the resin matrix is maintained. With minimised shrinkage stress, the integrity of the restoration especially at the margins is ensured. In this way Kalore offers you a revolutionary total package in aesthetic restorations: extended longevity and durability - sustained form and function; excellent handling - complete control is in your hands; and superior aesthetics - perfection created and maintained for a longer time. It is indicated for class I, II, III, IV and V cavities; wedge shaped defects and root surface cavities; and veneers and diastema closure.

For further information contact GC UK. Reader response number 56

\section{AVOID SPLATTER AND SPRAY}

Comfort Relax and Comfort Light from QED are extremely cost effective protective visors. Suitable for use in all aspects of dental treatment they are extremely comfortable to wear and protect the wearer's face from all the 'splatter 'n' spray' associated with most dental procedures. Lightweight and hygienic they can be worn in association with conventional corrective glasses.

Available in a choice of seven colours, they are available in two types. Comfort Relax has metal clips and can be used in conjunction with all the types of foil currently available on the market. Comfort Light has the lightest frame on the market and features special plastic holders rather than metal clips. Both styles are supplied with four Comfort Foils, providing crystal clear clarity. Reader response number $\mathbf{5 7}$ 